\title{
CONTROLE DA ATIVIDADE ECONÔMICA PELO ESTADO - CASO DAS EMPRESAS ESTAMPADORAS DE PLACAS DE IDENTIFICAÇÃO VEICULAR NO ESTADO DO PARANÁ
}

\author{
CONTROL OF ECONOMIC ACTIVITY BY THE STATE - CASE OF VEHICLE \\ IDENTIFICATION PLATE STAMPING COMPANIES IN THE STATE OF \\ PARANÁ
}

\author{
Sandro Mansur Gibran ${ }^{1}$ \\ Demetrius Nichele Macei $^{2}$ \\ Caroline Alessandra Taborda Dos Santos Dallegrave ${ }^{3}$
}

\section{RESUMO}

O presente estudo busca analisar os efeitos da utilização de nomenclatura idêntica para significados distintos. O termo credenciamento é uma criação doutrinária e que foi utilizada em texto de Lei no Estado do Paraná para tratar de procedimento de contratação com a administração pública, mas também foi utilizado pelo CONTRAN com o significado de autorização de atividade econômica, nos termos do art. 170 da Constituição Federal. Assim, o objetivo foi analisar os efeitos jurídicos e econômicos da aplicabilidade de credenciamento no Estado do Paraná no âmbito da atividade econômica de estampagem de placas de identificação veicular. Adotou-se a metodologia da pesquisa bibliográfica. Como resultado desta análise, foi possível verificar que o credenciamento poder ser utilizado como

\footnotetext{
${ }^{1}$ Doutor em Direito Econômico e Socioambiental pela Pontifícia Universidade Católica do Paraná (2009). Mestre em Direito Social e Econômico pela Pontifícia Universidade Católica do Paraná (2003). Graduado em Direito pela Faculdade de Direito de Curitiba (1996). É advogado. Professor de Direito Empresarial junto ao Centro de Estudos Jurídicos do Paraná CEJPR e na Escola da Magistratura Federal do Paraná ESMAFE/PR. Professor visitante na Universidade da Indústria da Federação das Indústrias do Estado do Paraná UNINDUS. Coordenador do Curso de Pós-Graduação em Direito Empresarial do UNICURITIBA. Coordenador do Curso de Pós-Graduação em Direito Contratual do UNICURITIBA. Professor permanente no Programa de Mestrado e Doutorado em Direito Empresarial e Cidadania do UNICURITIBA.

${ }^{2}$ Pós-doutorado na Faculdade de Direito do Largo São Francisco (USP). Doutor em Direito Tributário pela Pontifícia Universidade Católica de São Paulo (2012). Mestre em Direito Econômico e Social (2004) e Especialista em Direito Empresarial (2000), ambos pela Pontifícia Universidade Católica do Paraná, Bacharel em Direito pela Universidade Federal do Paraná (1994). Professor de Direito Tributário na graduação, especialização, mestrado e doutorado na Faculdade de Direito Curitiba (UNICURITIBA)

${ }^{3}$ Bacharela em Direito pela Pontifícia Universidade Católica do Paraná - PUC/PR. Pós-Graduada em Direito Aplicado pela Escola da Magistratura do Paraná - EMAP/PR. Especialista em Direito Administrativo pelo Instituto Romeu Felipe Bacellar. Acadêmica do Curso de Mestrado - Centro Universitário Curitiba UNICURITIBA. Curitiba - PR. E-mail: caroline.taborda@ hotmail.com.
} 
procedimento licitatório ou como ato de autorização de exercício de atividade econômica. Contudo, para a atividade de estamparia de placas de identificação veicular o modelo econômico e jurídico adequado é de credenciamento autorizador do exercício da atividade. Ao passo que o ato de emplacar o veículo é de competência da Administração Pública e, portanto, pode ser prestado por meio de credenciamento licitatório por empresas privadas.

Palavras-chave: empresa, credenciamento, autorização, estado.

\begin{abstract}
The present study seeks to analyze the effects of using identical nomenclature for different meanings. The term accreditation is a doctrinal creation and was used in a text of Law in the State of Paraná to deal with the contracting procedure with the public administration, but it was also used by CONTRAN with the meaning of authorization of economic activity, under the terms of art. 170 of the Federal Constitution. Thus, the objective was to analyze the legal and economic effects of the applicability of accreditation in the State of Parana within the scope of the economic activity of stamping vehicle identification plates. Bibliographic research methodology was adopted. As a result of this analysis, it was possible to verify that accreditation can be used as a bidding procedure or as an authorization to exercise economic activity. However, for the stamping activity of vehicle nameplates, the appropriate economic and legal model is of accreditation that authorizes the exercise of the activity. While the act of registering the vehicle is the responsibility of the Public Administration and, therefore, can be provided through bidding accreditation by private companies.
\end{abstract}

Key-words: company, accreditation, authorization, state.

\title{
1. INTRODUÇÃO
}

O ordenamento jurídico brasileiro é pautado na livre iniciativa e na livre concorrência, conforme prevê a Constituição da República do Brasil (BRASIL, 1988). Assim, o empreendedorismo é mote de desenvolvimento econômico, no qual a atividade empresarial, via de regra, independe de autorização de órgãos públicos, conforme previsto no art. 170, parágrafo único: "é assegurado a todos o livre exercício de qualquer atividade econômica, independente de autorização de órgãos públicos, salvo nos casos previstos em lei". (BRASIL, 1988). 
Portanto, existindo a exceção à regra, cumpre ao Estado autorizar o exercício de determinadas atividades econômicas mediante lei. Trata-se, pois, de atribuição decorrente do Poder de Polícia do Estado.

Outra atribuição do Estado é a de prestador de Serviço Público, cuja titularidade de sua prestação pode ser conferida a entidades estranhas ao aparelho administrativo, como o caso de Concessão realizada por Parceria Público Privada.

Diante destas atribuições do Estado sobre atividades econômicas dos particulares, é que o presente artigo visa evidenciar a diferença entre o exercício de tais deveres do Estado e como a interpretação equivocada pode impactar na atividade econômica privada.

Para ilustrar a diferenciação entre os institutos supracitados e o impacto econômico na atividade empresarial, é que será apresentado o caso concreto das normas aplicadas às empresas que fabricam e estampam placas de identificação veicular, mediante análise sobre o controle e a regulação do Estado sobre a atividade econômica de fabricação e estamparia de placas de identificação veicular no Estado do Paraná, a redação e interpretação das normas aplicadas à atividade.

\section{DO CONTROLE E REGULAÇÃO DO ESTADO SOBRE ATIVIDADE ECONÔMICA}

A proteção constitucional da livre iniciativa propicia a todos o direito de exercício da atividade econômica, com o objetivo que assegurar a todos a existência digna, com a valoração da livre iniciativa e do trabalho digno.

A livre iniciativa é um direito fundamental previsto em três momentos da Constituição de 1988. Está presente no inciso IV do artigo 10, no inciso XIII, do artigo $5^{\circ}$, e no parágrafo único do art. 170 (BRASIL, 1988).

Em consonância com a livre iniciativa o Princípio da Supremacia do Interesse Público sobre o interesse Privado, princípio geral do Direito e inerente a qualquer sociedade, é um pressuposto lógico do convívio social. Como extensão desta supremacia a Administração pode, nos termos da lei, constituir terceiros em obrigações mediante atos unilaterais, traduzida na previsão legal de sanções ou providencias indiretas que induzam o administrado a acatá-los.

A própria administração pode executar a pretensão traduzida no ato sem a necessidade de recorrer previamente às vias judiciais para obtê-la, trata-se da autoexecutoriedade dos atos administrativos. Esta ocorre apenas em duas hipóteses: quando há previsão legal ou quando a provisão for urgente ao ponto de demandá-la de imediato, quando não houver outra via de igual eficácia e existir serio risco de perecimento do interesse público se não for adotada (BANDEIRA DE MELLO, 2008). 
Contudo, a extensão da supremacia da Administração e seu controle e regulação devem estar em consonância com o exercício da livre iniciativa, para que seja perseguido o equilíbrio entre o desenvolvimento de atividades econômicas e a atuação estatal. Nesta seara é que Humberto Bergmann Ávila conclui em sua obra: "Repensando o 'Princípio da Supremacia do interesse público sobre o particular":

“[...] O que deve ficar claro, porém, é que, mesmo nos casos em que ele legitima uma atuação estatal restritiva específica, deve haver uma ponderação relativamente aos interesses privados e à medida de sua restrição. É essa ponderação para atribuir máxima realização aos envolvidos o critério decisivo para a atuação administrativa. E antes que este critério seja delimitado, não há cogitar sobre a referida supremacia do interesse público sobre o particular." (ÁVILA, 1999).

No mesmo sentido é que a Constituição da República impulsiona a mudança do Estado Social ${ }^{4}$ para o Estado Regulador ${ }^{5}$, consubstanciando no seu art. 174 (BRASIL, 1988):

"Como agente normativo e regulador da atividade econômica, o Estado exercerá, na forma da lei, as funções de fiscalização, incentivo e planejamento, sendo este determinante para o Setor Público e indicativo para o Setor Privado.”

O Estado coloca-se na posição de regulador, retirando-se da posição de prestador de serviços, característica do Estado Social. "É cediço que o interesse público não se traduz em objetivo perseguido pelo Capital, no entanto, é a razão da existência do Estado e, para tanto, o modelo regulatório passa a significar uma alternativa de equilíbrio entre os interesses eminentes privados e os indisponíveis interesses públicos.” (MELO, 2010).

Evidente, pois, que no período denominado Estado Social a atuação Estatal era de execução e prestador de serviços, ao passo que no Estado Regulador, adota a posição de regulador. Esta diferenciação na atuação estatal evidencia a diferenciação objeto do presente estudo, entre prestação de serviço público e exercício de poder de polícia.

Para conceituar serviço público utilizaremos a definição proposta por Celso Antônio Bandeira de Mello:

"[...] toda atividade de oferecimento de utilidade ou comodidade material destinada à satisfação da coletividade em geral, mas fruível singularmente pelos administrados, que o Estado assume como pertinente a seus deveres e presta por si mesmo ou pro quem lhe faça as vezes, sob um regime de Direito Público portanto, consagrador de prerrogativas de supremacia e de restrições especiais -

\footnotetext{
4 “O Estado Social é responsável por intervir na sociedade com vistas a promover a igualdade social, reduzindo as desigualdades sociais provocadas pelo modelo anterior, o Estado Liberal. Configura-se um assistencialismo por parte do Estado, a intervenção estatal se dá em praticamente toda a sociedade, porém, este modelo é também dispendioso e burocrático. O Estado enfrenta críticas cerradas pela sua ineficiência, desperdício de recursos, morosidade, burocracia e corrupção." (MELO, 2010).

5 "Verifica-se a redefinição do papel do Estado na economia e de suas relações com a sociedade. O Estado retira-se da condição de executor e prestador de serviços e adota uma posição de Regulador, haja vista que o próprio Estado não poderia simplesmente permanecer alheio à exploração privada de atividades econômicas relevantes, em especial, por se tratar da prestação de serviços públicos à sociedade." (MELO, 2010).
} 
, instituído em favor dos interesses definidos como públicos no sistema normativo" (BANDEIRA DE MELLO, 2008)

Observados os Princípios que norteiam o conceito de serviço público, a titularidade de sua prestação pode ser conferida a entidades estranhas ao aparelho administrativo, como o caso de Concessão realizada por Parceria Público Privada.

No entanto, imperioso destacar que o Estado possui diversas atividades que não se enquadram como Serviço, dentre tais atividades tem-se o poder de polícia e a exploração estatal de atividade econômica.

Ainda, destaca Celso de Mello que não se pode confundir serviço público com atividades privadas que, por força de lei, necessitam de prévia autorização de órgãos públicos (art. 170 da Constituição Federal). Desta forma, atividade econômica pertinente aos particulares deve ser precedida de autorização destinada a verificar, no exercício da "polícia administrativa", se será desempenhada dentro de condições compatíveis com o interesse coletivo.

\subsection{O poder de polícia}

Segundo definição doutrinária de Marçal Justen Filho (JUSTEN FILHO, 2005), o poder de polícia (Poder de Polícia Administrativa) é a competência administrativa de disciplinar o exercício da autonomia privada para a realização de direitos fundamentais e da democracia, segundo os princípios da legalidade e da proporcionalidade. ${ }^{6}$ Essa atividade tem finalidade meramente regulamentar, ou seja, tornar concreta (administrativamente) as limitações impostas pela lei, observando a adequação dos meios aos fins. ${ }^{7}$

Define Celso de Mello quanto ao poder de polícia: o Estado, mediante lei, condiciona, limita o exercício da liberdade e da propriedade dos administrados, a fim de compatibilizá-las com o bem-estar social, trata-se, pois, da prática de atos preventivos, fiscalizadores e repressivos pelo Estado. (MELLO, 2008)

Portanto, ao tratar de poder de polícia, está diante do poder fiscalizador e autorizador do Estado e, não, da execução de serviços públicos. Bem como, o poder de polícia é exercido unicamente pela administração pública, não sendo tolerável sua delegação a particulares, pois o Estado Democrático de Direito importa o monopólio estatal da violência, evitandose, com isso, a possibilidade de instauração de conflito de interesses.

\footnotetext{
${ }^{7}$ Art. $2^{\circ}$, § único, inciso VI, da Lei 9.784/99: A Administração Pública obedecerá, dentre outros, aos princípios da legalidade, finalidade, motivação, razoabilidade, proporcionalidade, moralidade, ampla defesa, contraditório, segurança jurídica, interesse público e eficiência. [...] VI - adequação entre meios e fins, vedada a imposição de obrigações, restrições e sanções em medida superior àquelas estritamente necessárias ao atendimento do interesse público; [...]
} 


\begin{abstract}
"Outrora, o fundamento do Poder de Polícia está no princípio da predominância do interesse público sobre o particular, seja adotando medidas preventivas, ou impondo-se medidas coercitivas para o resguardo do bem coletivo - condições que atribuem à administração a posição de supremacia sobre os administrados.

A atribuição da competência de poder de polícia não se vincula à prática de ato ilícito de um particular. Ou seja, o poder de polícia não tem natureza sancionatória. Muito pelo contrário, o poder de polícia apresenta cunho preventivo, sendo orientado a prevenir uma lesão a direitos e a valores juridicamente tutelados.

Mas o poder de polícia também se traduz na implementação de providências materiais destinadas a efetivar a consumação da irregularidade ou a continuidade de situação antijurídica." (JUSTEN FILHO, 2005).
\end{abstract}

Há de se considerar que o Estado poderá exercer o seu poder de polícia (em sentido amplo) através de:

\begin{abstract}
“[...] a) atos normativos, através da edição de leis que criem limitações administrativas ao exercício dos direitos e das atividades individuais, estabelecendo-se normas gerais e abstratas dirigidas indistintamente às pessoas; disciplinando a aplicação da lei aos casos concretos, com a publicação de decretos, resoluções, portarias e instruções; b) atos administrativos e operações materiais de aplicação da lei ao caso concreto, compreendendo medidas preventivas (fiscalização, vistoria, ordem, notificação, autorização, licença), com o objetivo de adequar o comportamento individual à lei, e medidas repressivas (dissolução de reunião, interdição de atividade, apreensão de mercadorias deterioradas, etc.), com a finalidade de coagir o infrator a cumprir a lei. [...] " (DI PIETRO, 2010)
\end{abstract}

O Poder de polícia é classificado como Polícia Administrativa e Polícia judiciária. O exercício do poder de polícia administrativa destina-se a regular e limitar o exercício determinados direitos, por parte dos administrados, em conformidade com os parâmetros previstos em leis e demais normas administrativas, incidindo preferencialmente sobre a propriedade dos administrados. (GOMES, 2012). Polícia judiciária, por sua vez, compreende os atos de polícia praticados em caráter privativo por determinados órgãos especializados da Administração Pública, como aqueles que exercem funções relacionadas á segurança pública (art. 144, caput, da CF [...]).”

Desta forma, o exercício de atividade econômica pelo particular que pende de autorização da Administração Pública está sob a égide do Poder de Polícia Administrativa do Estado.

Poder este exercido pela Administração pública, em geral, dentro dos limites de suas respectivas competências legais, tendo como objeto a prevenção elou a repressão a ilícitos administrativos. Possível, entretanto, sua delegação a pessoas públicas administrativas, como as autarquias, ou as pessoas governamentais, como empresas públicas (GOMES, 2012).

Entretanto, imperioso destacar que empresas privadas podem desempenhar função instrumental e material em relação à atividade de polícia administrativa. A atuação do particular ocorrerá em ato preparatório ou sucessivo a pratica dos atos administrativos típicos de polícia administrativa, pela Administração Publica competente, como são as empresas 
operadoras de radares eletrônicos de velocidade, que aferem e monitoram os veículos, mas o ato de aplicação de eventual multa por infração é ato privativo e exercido pela Administração Pública competente (GOMES, 2012).

\section{DA REDAÇÃO DA LEI E SUA INTERPRETAÇÃO NO CASO DAS EMPRESAS ESTAMPADORAS DE PLACAS DE IDENTIFICAÇÃO VEICULAR, NO ESTADO DO PARANÁ}

No âmbito federal, a Lei n. 9.503 de 23 de setembro de 1997 - Código de Trânsito Brasileiro (CTB) traz em seu artigo 115 e parágrafos que a identificação externa de veículo compreende a placa dianteira e traseira, devendo ser lacrada e seguir as normas de especificação e modelos estabelecidos pelo CONTRAN.

\footnotetext{
“Art. 115. O veículo será identificado externamente por meio de placas dianteira e traseira, sendo esta lacrada em sua estrutura, obedecidas as especificações e modelos estabelecidos pelo CONTRAN."
}

O Conselho Nacional de Trânsito (CONTRAN) determina, por força da Resolução sob n 780 de 26 DE JUNHO DE 2019, que dispõe sobre o novo sistema de Placas de Identificação Veicular, em seu art. $6^{\circ}$ que a competência para credenciar empresas fabricantes de Placas de Identificação Veicular e fiscalizar a execução de atividade destas é do Departamento Nacional de Trânsito. E, por força do art. $7^{\circ}$, compete aos DETRAN credenciar as empresas estampadoras de placas de identificação veicular, bem como fiscalizar a execução das atividades, instalações, equipamentos, gestão de controle produtivo das estampadoras.

No artigo 10 desta Resolução do CONTRAN há a distinção entre fabricante e estampador de placas de identificação veicular (PIV), podendo-se resumir em: fabricante o produtor da chapa base da PIV e o estampador a empresa responsável pelo acabamento (estampagem do código alfanumérico) e comercialização com os proprietários de veículos.

Além da competência definida pelo CONTRAN, o artigo 22 do CTB prevê a competência dos Órgãos Executivos de Trânsito dos Estados ou do Distrito Federal (DETRAN):

\footnotetext{
“Art. 22. Compete aos órgãos ou entidades executivos de trânsito dos Estados e do Distrito Federal, no âmbito de sua circunscrição: I - cumprir e fazer cumprir a legislação e as normas de trânsito, no âmbito das respectivas atribuições; [...] III vistoriar, inspecionar quanto às condições de segurança veicular, registrar, emplacar, selar a placa, e licenciar veículos, expedindo o Certificado de Registro e o Licenciamento Anual, mediante delegação do órgão federal competente; [...] $\mathrm{X}$ - credenciar órgãos ou entidades para a execução de atividades previstas na legislação de trânsito, na forma estabelecida em norma do CONTRAN; [...]"
}

Possível verificar que o dever de utilizar placas de identificação nos veículo é derivado do poder de polícia do Estado, com o objetivo de fiscalizar o uso da propriedade 
privada (veículo), dentre as regras estabelecidas pelo Código de Trânsito Brasileiro e demais regras e normas.

O fornecimento deste produto (placa de identificação veicular) também é regulado e controlado pelo Estado que, por meio do seu poder de polícia, atribui competência ao CONTRAN e aos DETRAN para credenciar empresas fornecedoras aos proprietários de veículos.

A controvérsia instalada no Estado do Paraná, por sua vez, diz respeito a discussão a cerca da natureza jurídica do credenciamento das empresas previsto nas normas supracitadas.

Visto que o termo "credenciamento" tem sua definição prevista na doutrina, por aplicação do art. 25 da Lei Federal sob n ${ }^{\circ}$ 8.666/1993 e, previsto de forma expressa no art. 24 da Lei Estadual PR sob n ${ }^{\circ} 15.608 / 2007$.

\subsection{Do credenciamento}

O ordenamento brasileiro, em sua Constituição Federal de 1988 (art. 37, inciso XXI), determinou a obrigatoriedade da licitação para todas as aquisições de bens e contratações de serviços e obras, bem como para alienação de bens, realizados pela Administração no exercício de suas funções.

A licitação se presta para que a Administração Pública receba a oferta mais vantajosa, ou seja, a empresa que oferecer maiores vantagens será a escolhida para o fornecimento do produto ou do serviço, para aquisição de bens alienados pela administração pública ou para atuar nos regimes de concessão ou permissão em relação a serviço público.

Licitação é um procedimento vinculado a lei, cabendo a União legislar sobre normas gerais de licitação e contratação, em todas as modalidades, para a Administração Pública, direta e indireta, nas diversas esferas do governo, e empresas sob seu controle (CF, art. 22, XXVII). Portanto, aos Estados, Distrito Federal e Municípios compete legislar suplementarmente sobre a matéria no que tange ao interesse peculiar de suas administrações.

Contudo, quando for inviável a competição para contratar com a Administração Pública, em razão de várias empresas poderem fornecer produto ou serviço em igualdade de condições, está diante de uma causa de inexigilibilidade de licitação, previsto no art. 25 da Lei Geral de licitações (lei federal sob no 8.666/1993) e que é defino pela doutrina como "credenciamento":

"Se a Administração convoca todos os profissionais de determinado setor, dispondo-se a contratar os que tiverem interesse e que satisfaçam os requisitos estabelecidos, ela própria fixando o valor que se dispõe a pagar, os possíveis licitantes não competirão, no estrito sentido da palavra, inviabilizando a competição, uma vez que a todos foi assegurada à contratação.”(JACOBY, 2008) 
No estado do Paraná, a Lei 15.608/2007 que trata das contratações realizadas pela administração pública do Estado que envolva, portanto, recursos públicos. Define licitação como uma forma da administração selecionar um único fornecedor para satisfazer seu interesse enquanto administração pública. Contudo, quando mais de um fornecedor pode atender esta necessidade é que se está diante de hipótese de credenciamento, conforme preceitua o art. 24:

\footnotetext{
"Credenciamento é ato administrativo de chamamento público, processado por edital, destinado à contratação de serviços junto àqueles que satisfaçam os requisitos definidos pela Administração, observado o prazo de publicidade de no mínimo 15 (quinze) dias úteis e no máximo de 30 (trinta) dias úteis.

Parágrafo único. A Administração Estadual poderá adotar o credenciamento para situações em que o mesmo objeto possa ser realizado simultaneamente por diversos contratados."
}

A hipótese de credenciamento trazida na lei estadual é de um procedimento auxiliar a Licitação, ou seja, para que a Administração Pública contrate serviços para seu consumo ou pra desempenhar suas funções, como a prestação de serviços públicos, pode se valer do procedimento de credenciamento.

Evidente, pois, que se está diante de uma relação contratual entre empresa prestadora de serviços e a Administração Pública, podendo o usuário do serviço ser tanto a própria Administração ou os administrados.

No que tange a atividade econômica de fabricação e estampagem de placas de identificação veicular, trata-se de fornecimento de produtos cuja relação contratual é estabelecida entre a empresa e o consumidor, proprietário do veiculo a que a placas de identificação se destina.

Inexiste alocação de recursos públicos, bem como não se trata de uma atividade de competência da Administração pública. Isto porque o CONTRAN, órgão competente para definir as regras e formas de emplacamento veicular (de acordo com o art. 115 do CTB) determina que o produto PIV seja fornecido diretamente pela empresa estampadora ao consumidor proprietário do veículo:

\footnotetext{
"13. Os estampadores credenciados deverão realizar, sob sua única, exclusiva e indelegável responsabilidade, a comercialização direta com os proprietários dos veículos, sem intermediários ou delegação a terceiros a qualquer título, definindo de forma pública, clara e transparente o preço total da PIV." (Resolução 780/2019, CONTRAN).
}

Assim, tais empresas atuam de forma instrumental ao exercício do poder de polícia da Administração pública perante os proprietários de veículos, não podendo ser confundida com prestação de serviço público. Ainda, as empresas estão submetidas ao mesmo poder de polícia da Administração Pública na forma e modo de atuação de sua atividade econômica, pelo ato que autoriza o exercício da atividade (Resolução 780/2019, CONTRAN): 


\begin{abstract}
"Art. 11. Os fabricantes de PIV serão credenciados pelo DENATRAN, conforme critérios estabelecidos no Anexo III. § $1^{\circ}$ Os fabricantes de PIV têm como finalidade a produção da placa semiacabada, bem como a logística, gerenciamento informatizado e distribuição das PIV aos estampadores credenciados. $\S 2^{\circ} \mathrm{Os}$ fabricantes credenciados na forma desta Resolução poderão fornecer PIV para todas as Unidades da Federação, vedada qualquer restrição ao exercício dessa atividade por parte dos DETRAN. § $3^{\circ}$ É vedado aos fabricantes firmarem contratos de exclusividade com os estampadores, sob pena de descredenciamento. $\S 4^{\circ}$ Os fabricantes somente poderão fornecer PIV para estampadores credenciados pelos DETRAN, para que estes realizem a estampagem e o acabamento final. $\S 5^{\circ}$ Cabe ao fabricante disponibilizar equipamentos e sistemas informatizados para garantir a prevenção contra as fraudes e operações não autorizadas, bem como todas as informações relativas ao histórico dos processos realizados, nos termos estabelecidos pelo DENATRAN."
\end{abstract}

"Art. 12. Os estampadores de PIV serão credenciados pelos respectivos DETRAN, em sistema informatizado do DENATRAN, conforme critérios estabelecidos no Anexo III. § $1^{\circ}$ Os estampadores têm como finalidade executar a estampagem e o acabamento final das PIV. $\S 2^{\circ}$ Os estampadores poderão adquirir PIV e insumos de qualquer fabricante regularmente credenciado pelo DENATRAN, independentemente da Unidade da Federação de sua instalação. $\S 3^{\circ}$ Os estampadores deverão emitir a nota fiscal diretamente ao consumidor final, sendo vedada a sub-rogação dessa responsabilidade."

Possível verificar, então, que o termo "credenciamento" previsto na resolução do CONTRAN trata de "autorização", pois Embora a fabricação e estampagem de placas se enquadre como típica atividade de exploração econômica, com regime de direito privado e com fundamento constitucional no exercício da livre iniciativa, sua atuação comercial depende de prévia autorização do DENATRAN e do respectivo DETRAN da unidade da federação em que será fornecido o produto, bem como seu exercício deve ser continuamente fiscalizado pelo órgão responsável, uma vez que se enquadra na exceção trazida pelo artigo 170, § único, da Constituição Federal: "É assegurado a todos o livre exercício de qualquer atividade econômica, independentemente de autorização de órgãos públicos, salvo nos casos previstos em lei”.

Uma vez que as atividades de fabricação e de estamparia de placas de identificação veicular não são atividades de competência do Estado, mas sim atividade econômica a ser explorada pelo ente privado, está regida pelo Princípio Constitucional da Livre Iniciativa e submetidas à autorização (credenciamento) da Administração pública.

\title{
3.2. Efeitos do Credenciamento Licitatório e do Credenciamento Autorizador no desenvolvimento da atividade econômica da empresa
}

A liberdade de iniciativa trazida pela Constituição Federal (Brasil, 1988) prestigia o reconhecimento de um direito titularizado por todos que é o de explorarem as atividades empresariais, decorrendo no dever, imposto à generalidade das pessoas, de 
respeitarem o mesmo direito constitucional, bem como a caracteriza como ilicitude atos que impeçam o seu pleno exercício e que se contrapõe ao próprio estado.

Neste sentido, art. 139 da Constituição Estadual do Paraná (PARANÁ, 1989), dispõem como princípio da ordem econômica "a organização da atividade econômica, fundada na valoração do trabalho, na livre iniciativa e na proteção do meio ambiente, tem por objetivo assegurar existência digna a todos, conforme os mandamentos da justiça social e com base nos princípios estabelecidos na Constituição Federal”.

Assim, o Princípio constitucional da livre iniciativa permite que pessoas físicas constituam pessoas jurídicas para desenvolver atividades econômicas e contribuir para o desenvolvimento da ordem econômica. Contudo, o vínculo que a empresa possui com a Administração Pública reflete diretamente na forma de sua operação como no seu resultado econômico.

Quando a empresa atua em atividade que não depende de autorização da Administração Pública para o seu exercício, tem plena liberdade de atuação, estando impedida, apenas, de praticar atos defesos em lei. Como o caso de Lei de propriedade industrial, atos de concorrência desleal ou atos de caracterizem infração à ordem econômica, por exemplo.

Ao passo que, esta mesma empresa, pode participar de um procedimento licitatório para fornecer determinado bem ou serviço à Administração Pública, ou aos administrados, mediante remuneração com recursos públicos (total ou parcial). Além das regras gerais que regem a atividade econômica e as pessoas jurídicas de direito privado, a empresa estará submetida aos regramentos do Contrato Público, que por sua essência não possui a bilateralidade contumaz de contratos entre pessoas de direito privado. Estará sujeita, pois, a cláusulas exorbitantes que derivam da supremacia do interesse público e permite a alteração unilateral do contrato pela Administração Pública, e o controle desta do contrato, a exigência de garantias, entre outras peculiaridades da contratação com a Administração Pública.

Para o sistema de emplacamento veicular havia Unidade da Federação, em momento anterior a entrada em vigor da Resolução 780 do CONTRAN, que optava por fornecer as placas de identificação veicular aos proprietários de veículos por meio de aquisição pelo DETRAN, por procedimento licitatório, e venda aos usuários. Com esta intervenção da Administração o resultado era uma empresa como fornecedora exclusiva do Estado atendendo toda a frota de veículos registrados naquele Estado.

Com a determinação de credenciamento trazida na Resolução, o procedimento foi alterado, bem como o a ordem econômica local. No Estado em que apenas uma empresa era fornecedora, não há mais limitação do número de empresas, desde que cumpram os requisitos previstos no Edital de chamamento para credenciamento. Ou seja, a movimentação da economia, com vários agentes atuando proporcionando diferentes preços ao consumidor e a opção de escolha de qual empresa deseja adquirir o produto.

Portanto, ao deixar de se estabelecer relação contratual entre a empresa e a Administração Pública, inaplicável o credenciamento doutrinário derivado da inexigilidade de licitação da Lei 8.666/93, mas sim evidente que se trata apenas de autorização da Administração Púbica para o exercício da atividade econômica das empresas no referido Estado. 
Contudo, no Estado do Paraná em decorrência de Lei que traz a definição e procedimento para credenciamento, instaurou-se a controvérsia sobre se tratar de um credenciamento licitatório ou se o credenciamento autorizador da atividade. Como já explicitado em tópico anterior, evidente que se trata de um credenciamento autorizador decorrente do Poder de Polícia Administrativa da Administração Púbica, mas crível destacar os efeitos econômicos destes institutos no Estado do Paraná.

Para que a atividade seja submetida ao credenciamento licitatório é imprescindível que haja contratação com a Administração Pública, visto que a Lei 15.608/2007 dispõem sobre: Estabelece normas sobre licitações, contratos administrativos e convênios no âmbito dos Poderes do Estado do Paraná. Bem como, deve tratar de prestação de serviços conforme previsto no art. 24 da Lei.

A atividade de produção e comercialização de PIV trata de manufatura, portanto, fornecimento de produto e, não de prestação de serviço. Situação que gera inaplicabilidade da referida lei, além da determinação do CONTRAN de que a comercialização seja direta, entre empresa e consumidor.

Contudo, ao analisar os requisitos legais para o referido credenciamento, é possível estimar os efeitos econômicos desta modalidade de contratação. São requisitos para a empresa que pretende o credenciamento (art. 25): prestar o serviço de acordo com a tabela de preços definida; rotatividade entre os credenciados; vedado o recebimento de qualquer sobretaxa em relação à tabela adotada; pagamento pela Administração conforme a demanda, com base em valor pré-definido pela Administração.

Além do tabelamento dos preços, o que inviabiliza a competição entre fornecedores e retira o poder de barganha aos consumidores, a rotatividade do fornecimento impede o consumidor de escolher de qual empresa vai adquirir o seu produto. Situação que desestimula a empresa ao desenvolvimento comercial de sua atividade e melhora em seu atendimento, pois o "cliente" já está garantido. O número de colaboradores desta empresa também será limitado, apenas o mínimo necessário para atender a demanda determinada, sem qualquer projeção de aumento de seus ganhos por empenho ou ações próprias. E, como se trata de um fornecimento de produto sem concorrência direta, o padrão de qualidade e as garantias serão apenas as exigidas pela Administração Pública.

A busca legítima pelo lucro que movimenta a ordem econômica, promove a geração de empregos e propicia o atendimento de melhor qualidade ao consumidor, ficam em risco. Razão pela qual esta modalidade de contratação (credenciamento licitatório) é utilizada para prestação de serviço de titularidade pública e não para fornecimento de produtos pela iniciativa privada aos consumidores.

Ao passo que o credenciamento autorizador revela maior eficiência econômica dos agentes, pois apenas determina as regras para o exercício da atividade e a forma de relacionamento com a Administração Publica autorizadora da atividade, sem interferir na atuação comercial das empresas, que por estarem na livre iniciativa devem praticar suas estratégias comerciais sem interferência direta no preço ou na concorrência entre elas, excetuando, por óbvio, os atos defesos por lei.

Percebe-se, pois, que a eficiência econômica, a circulação de riquezas e a geração de empregos é fomentada, no caso da atividade de fabricação e estamparia de placas de 
identificação veicular, pela Administração Pública por meio do credenciamento autorizador, sem que a segurança típica e necessária para o exercício desta atividade seja comprometida.

\subsection{Dos atos de emplacar e de selar a placa.}

A distinção entre as atividades de fabricação e estampagem de placas de identificação veicular está estabelecida claramente na Resolução 780 do CONTRAN (art. 11 e 12). Contudo, omissa sobre os atos de emplacar e de selar a placa no veículo.

Embora pareça que tais atividades são intrínsecas ao ato de comercialização, não são por decorrência da competência instituída no Código de Trânsito Brasileiro. Como já citado alhures, o art. 22, no inciso III, ao estabelecer a competência dos órgãos ou entidades executivas de trânsito (DETRAN), impõe-lhes o dever de emplacar e de selar a placa.

Portanto, estas atividades são de competência da Administração Pública e para que sejam executadas por empresas privadas, devem ocorrem mediante delegação de serviço público.

Situação que se amolda ao caso do credenciamento licitatório, uma vez que trata de serviço: ato de emplacar e selar a placa; e pode ser executado por várias empresas simultaneamente. Mesmo após a alteração do CTB com a inclusão do parágrafo nono que permite a utilização de tecnologia que permita identificar o veículo ao qual a placa está atrelada, e assim, dispensando o lacre de placas, o serviço de emplacar (instalar a placa do veículo) ainda é de titularidade da Administração pública.

Razão pela qual, para que a empresa fornecedora da PIV instale-a no veículo, deve ser prestadora do serviço público. Assim, a mesma empresa terá dois vínculos distintos com o DETRAN, um de credenciamento autorizador do exercício da atividade econômica de estamparia de placas e outra de credenciamento licitatório para prestar o serviço de instalação das placas de identificação veicular no veículo.

Existe, ainda, a possibilidade a placa ser instalada pelo próprio DETRAN. Mas não mais pode ser feito por despachantes de trânsito, como eram anteriormente à Resolução 780/2019 do CONTRAN. Porque a Lei estadual sob nº 17.682/2013, em seu art. 12, inc. II, que estabelece a competência dos despachantes de trânsito, limita sua atuação a "lacrar placas" ao veículo e, como o lacre foi dispensado pelo CTB e pelo CONTRAN fica esvaziada esta competência. Também não é possível interpretar a lei extensivamente para o âmbito do emplacamento, uma vez que se trata de ato administrativo que não permite interpretação extensiva.

A Administração Pública está adstrita ao princípio da legalidade e, por isso, não pode interpretar de forma extensiva ou restritiva os direitos quando a lei assim não o prevê de modo expresso, nesse sentido, a lição de Celso Antônio Bandeira de Mello:

\footnotetext{
"No Estado de Direito a Administração só pode agir em obediência à lei, esforçada nela e tendo em mira o fiel cumprimento das finalidades assinaladas na ordenação normativa. Como é sabido, o liame que vincula a Administração à lei é mais estrito que o travado entre a lei e o comportamento dos particulares. Com efeito, enquanto
} 
na atividade privada pode-se fazer tudo o que não é proibido, na atividade administrativa só se pode fazer o que é permitido. Em outras palavras, não basta a simples relação de não-contradição, posto que, demais disso, exige-se ainda uma relação de subsunção. Vale dizer, para a legitimidade de um ato administrativo é insuficiente o fato de não ser ofensivo à lei. Cumpre que seja praticado com embasamento em alguma norma permissiva que lhe sirva de supedâneo." (BANDEIRA DE MELLO, 2010).

E, como o despachante de trânsito é pessoa credenciada ao DETRAN para prestar serviços de titularidade deste, deve seguir os princípios e normas que regem a administração pública. Assim como o DETRAN por integrar a administração pública do Estado do Paraná, na qualidade de autarquia.

Desta forma, o desempenho do serviço de emplacamento é de competência dos DETRAN e deve seguir as normativas de direito administrativo, diferentemente, da atividade de fabricação e estamparia de placas que está na livre iniciativa.

\section{CONSIDERAÇÕES FINAIS}

A nomenclatura a ser utilizada na esfera jurídica deve ser analisada de acordo com a natureza jurídica, pois interpretação diversa pode gerar efeitos jurídicos e alterações significativas nas atividades desenvolvidas.

O caso das fábricas e estampadores de placas de identificação veicular revela que a utilização da nomenclatura "credenciamento" como autorização para exercício da atividade econômica pelo particular, ao ser confundido com o "credenciamento" de procedimento licitatório altera totalmente a forma de tutelar a atividade econômica.

O CONTRAN, por competência definida pelo Código de trânsito Brasileiro, determina que pessoas jurídicas de direito privado devem fornecer as placas de identificação veicular diretamente aos consumidores. E cabe ao DETRAN, através do seu poder de polícia, autorizar a atuação destas empresas, o que foi chamado de credenciamento, além de fiscalizar sua atuação.

Desta feita, a nomenclatura utilizada como credenciamento, serve para configurar autorização, a mesma prevista na Constituição Federal no art. 170, parágrafo único: “é assegurado a todos o livre exercício de qualquer atividade econômica, independente de autorização de órgãos públicos, salvo nos casos previstos em lei”.

Assim, a natureza jurídica da atividade está na livre iniciativa e não é uma atividade desenvolvida ou de titularidade da administração pública. Mas sim, ao seu poder de polícia em autorizar a atividade e de fiscalizar sua atuação.

Quem adquire as placas são os consumidores e quem fornece são as empresas autorizadas a exercerem a atividade. A relação jurídica na aquisição do produto é fornecedor - consumidor, sem que a Administração Pública seja partícipe. A relação do DETRAN é apenas com a empresa, de cunho fiscalizador, ou seja, não há utilização de recursos públicos ou de representação da administração pública perante o cidadão pela empresa. 
As normas aplicadas ao credenciamento licitatório trazem a empresa como uma prestadora de serviço público, estando sujeita, pois, a normativa de direito público e, quando se trata de credenciamento autorizador a empresa atua na livre iniciativa, sujeitas às regras de direito público que regem a autorização da atividade perante o órgão da administração pública que a autorizou.

Para as empresas o efeito é econômico, além de normativo. Custear uma atividade econômica caracterizada como serviço público pode reduzir significativamente os seus custos estruturais, mais aumentar seu custo de produção e operação, pois trabalha com demanda determinada, em sistema de rodízio sem a possibilidade de aumentar sua atuação e nem de prospectar novos clientes.

Razão pela qual é possível constatar maior eficiência econômica do agente atuante, neste caso, na livre iniciativa, mesmo que de forma regulada e autorizada pela Administração Pública, no modelo de credenciamento autorizador.

Ao passo que, a atividade de emplacar o veículo é de competência legal dos órgãos ou entidades executivas de trânsito (DETRAN) e, para que sejam executados por empresas privadas, devem ser feitos mediante delegação de serviço público.

\section{REFERÊNCIAS}

Lei Estadual $\mathrm{n}^{\mathbf{0}} \mathbf{1 5 . 6 0 8}$, de 16 de agosto de 2007. Estabelece normas sobre licitações, contratos administrativos e convênios no âmbito dos Poderes do Estado do Paraná. Diário Oficial [da] Estado do Paraná, Palácio do Governo, PR, 16 ago. 2007. Disponível em: <https://www.legisweb.com.br/legislacao/?id=323836>. Acesso em: 16 fev. 2020.

Lei Estadual $n^{\circ}$ 17.682, de 20 de setembro de 2013. Dispõe sobre as atividades profissionais de Despachante de Trânsito, perante o Departamento de Trânsito do Paraná DETRAN-PR. Diário Oficial [da] Estado do Paraná, Palácio do Governo, PR, 20 set. $2013 . \quad$ Disponível em: $<$ http://www.detran.pr.gov.br/arquivos/File/Despachante/lei_despachante_20_09_13.pdf $>$. Acesso em: 16 fev. 2020.

Lei Federal $\mathrm{n}^{\mathrm{o}} \mathbf{1 0 . 4 0 6}$, de 10 de janeiro de 2002. Institui o Código Civil Brasileiro. Diário Oficial [da] República Federativa do Brasil, Brasília/DF, 11 jan. 2002. Disponível em: <http://www.planalto.gov.br/ccivil_03/leis/2002/110406.htm>. Acesso em: 16 fev. 2020.

Lei Federal $n^{\circ}$ 8.666, de 21 de junho de 1993. Regulamenta o art. 37, inciso XXI, da Constituição Federal, institui normas para licitações e contratos da Administração Pública e dá outras providências. Diário Oficial [da] República Federativa do Brasil, Brasília/DF, 21 jun. 1993. Disponível em: <http://www.planalto.gov.br/ccivil_03/leis/18666cons.htm >. Acesso em: 16 fev. 2020.

Lei Federal $n^{\circ}$ 9.503, de 23 de setembro de 1997. Institui o Código de Trânsito Brasileiro. Diário Oficial [da] República Federativa do Brasil, Brasília/DF, 23 set. 1997. 
Disponível em: <http://www.planalto.gov.br/ccivil_03/leis/19503.htm>. Acesso em: 16 fev. 2020.

Lei Federal $\mathrm{n}^{\mathrm{o}}$ 12.529, de 30 de novembro de 2011. Dispõe sobre Estrutura o Sistema Brasileiro de Defesa da Concorrência; dispõe sobre a prevenção e repressão às infrações contra a ordem econômica; altera a Lei no 8.137, de 27 de dezembro de 1990, o Decreto-Lei no 3.689, de 3 de outubro de 1941 - Código de Processo Penal, e a Lei no 7.347, de 24 de julho de 1985; revoga dispositivos da Lei no 8.884, de 11 de junho de 1994, e a Lei n 9.781, de 19 de janeiro de 1999; e dá outras providências. Diário Oficial [da] República Federativa do Brasil, Brasília/DF, 01 jan. 2011. Disponível em: $<$ http://www.planalto.gov.br/ccivil_03/_ato2011-2014/2011/lei/l12529.htm>. Acesso em: 16 fev. 2020.

. Lei Federal no 9.279, de 14 de maio de 1996. Dispõe sobre Regula direitos e obrigações relativos à propriedade industrial. Diário Oficial [da] República Federativa do Brasil, Brasília/DF, 15 maio $1996 . \quad$ Disponível em: <http://www.planalto.gov.br/ccivil_03/Leis/L9279.htm>. Acesso em: 16 fev. 2020.

Resolução do CONSELHO NACIONAL DE TRÂNSITO nº 780, de 26 de junho de 2019. Dispõe sobre o novo sistema de Placas de Identificação Veicular. Diário Oficial [da] República Federativa do Brasil, Brasília/DF, 26 jun. 2019. Disponível em: $<$ https://infraestrutura.gov.br/images/Resolucoes/Resolucao7802019.pdf $>$. Acesso em: 16 fev.

$<$ http://revista.cade.gov.br/index.php/revistadedefesadaconcorrencia/issue/view/20>.

$\begin{array}{lllll}\text { Acesso } & \text { em } & 14 & \text { fev. } & 2020 .\end{array}$ http://revista.cade.gov.br/index.php/revistadedefesadaconcorrencia/article/view/424

ÁVILA, Humberto Bergmann. Repensando o Princípio da supremacia do interesse público. O Direito Público em Tempos de Crise - Estudos em Homenagem a Ruy Ruben Ruschel, 1999, p. 99-127.

BANDEIRA DE MELLO, Celso Antonio. Curso de Direito Administrativo. 26 ed. - São Paulo: Malheiros, 2008, p.96

BRASIL. Constituição Federal, de 5 de outubro de 1988. Diário Oficial [da] República Federativa do Brasil, Brasília, DF, 6 out. 1988. Disponível em: $<$ http://www.planalto.gov.br/ccivil_03/Constituicao/ConstituicaoCompilado.htm $>$. Acesso em: 15 fev. 2020.

CASAGRANDE, Paulo. INOVAÇÃO, COOPERAÇÃO E CONCORRÊNCIA: DESAFIOS PARA A POLÍTICA ANTITRUSTE NO BRASIL. 2014. 320f. Tese (Doutorado em Direito Econômico). Faculdade de Direito da Universidade de São Paulo, São Paulo, São Paulo, 2014.

CONSELHO ADMINISTRATIVO DE DEFESA ECCONÔMICA (CADE). Perguntas sobre infrações à ordem econômica. O que é concorrência desleal? 2016. Disponível em: $<$ http://www.cade.gov.br/servicos/perguntas-frequentes/perguntas-sobre-infracoes-aordem-economica>. Acesso em 22 ago. 2019. 
CONSULTOR JURÍDICO (CONJUR). MONOPÓLIO DA CARTA. Correios pagarão multa de R\$ 21,9 milhões por concorrência desleal, decide Cade. 2019. Disponível em: $<$ https://www.conjur.com.br/2019-jan-30/correios-pagarao-multa-219-milhoesconcorrencia-desleal>. Acesso em 22 ago. 2019.

DALLARI, Adilson Abreu. Revista Eletrônica de Direito do Estado. Número 5 Janeiro/fevereiro/março 2006 - Salvador /Bahia.

DI PIETRO, Maria Sylvia Zanella. Direito Administrativo. 23 ed. - São Paulo: Editora Atlas S/A, 2010, p. 113.

FILHO, Marçal Justen. Cometários à Lei de Licitações e Contratos Administrativos. 13 . Edição. Belo Horizonte: Dialética, 2009, p. 367.

FORGIONI, Paula A. Os fundamentos do Antitruste. $10^{\mathrm{a}}$ Ed. rev. - São Paulo: Thomson Reuters Brasil, 2018.

GASPARINI, Diógenes. Direito Administrativo. São Paulo: Saraiva, 1995.

GOMES, Fábio Bellote. Elementos do Direito Administrativo. 2 ed. - São Paulo: Saraiva, 2012.

INSTITUTO FÓRMULA. E-BOOK DE DIREITO ECONÔMICO. PROFESSOR MAURO MOREIRA. 2018. Disponível em: <https://www.institutoformula.com.br/wpcontent/uploads/2018/08/D.-Econo\%cc\%82mico-Introduc\%cc\%a7a\%cc\%83o-1.pdf>.

Acesso em 16 fev. 2020.

JACOBY, Jorge Ulisses. Coleção de Direito Público. Volume 6. Belo Horizonte: Fórum, 2008, p. 534.

JASPER, Eric. O PARADOXO TROPICAL: A FINALIDADE DA CONCORRÊNCIA NO BRASIL. Revista de Defesa da Concorrência, Vol. 7, $n^{\circ}$ 2, p. 171-189, nov. 2019. ISSN 2318-2253. Disponível em:

http://webcache.googleusercontent.com/search?q=cache:BUNQ51UE15oJ:revista cade gov. br/index.php/revistadedefesadaconcorrencia/article/view/424/242+\&cd=1\&hl=pt-

BR\&ct=clnk\&gl=br> Acesso em 18 de fev. de 2020.

MEIRELLES, Hely Lopes. Direito administrativo brasileiro. São Paulo: Malheiros Editores, 2004. 
MELO, Thiago Dellazari. DO ESTADO SOCIAL AO ESTADO REGULADOR. Revista do Curso de Mestrado em Direito da UFC, vol. 30, $\mathrm{n}^{\circ}$ 1, jan./jun. 2010. ISBN 1807-3840. Disponível em: <http://www.periodicos.ufc.br/nomos/article/view/1244> Acesso em 18 de fev. de 2020. <http://www.periodicos.ufc.br/nomos/issue/view/54>

MURPHY, Robert P. A Escola de Chicago versus a Escola Austríaca. MISSES BRASIL, 26 de jun. de 2011. Disponível em: <https://www.mises.org.br/article/1024/a-escola-dechicago-versus-a-escola-austriaca $>$ Acesso em 18 de fev. de 2020. $\langle$ https://www.mises.org.br/Default.aspx >

NETO, Fatuch Andre. ETICIDADE E BOA-FÉ NOS CONTRATOS EMPRESARIAIS: A VEDAÇÃO dAS PRÁTICAS ABUSIVAS. 2018. 145f. Dissertação (Mestrado em Direito Empresarial e Cidadania). Centro Universitário de Curitiba, Unicuritiba, Curitiba, Paraná, 2018.

OLIVEIRA, Marcella Gomes de; OPUSZKA, Paulo Ricardo. DIREITO E ATIVIDADE ECONÔMICA - UMA ANÁLISE INTERDISCIPLINAR SOBRE A INTERVENÇÃO ESTATAL. Revista Juridica, [S.1.], v. 2, n. 35, p. 445-463, nov. 2014. ISSN 2316-753X. Disponível em: <http://revista.unicuritiba.edu.br/index.php/RevJur/article/view/968/666>. Acesso em: 19 abr. 2020. doi:http://dx.doi.org/10.21902/revistajur.2316-753X.v2i35.968.

OLIVEIRA, Gustavo Justino de. Terceiro setor, empresas e Estado: novas fronteiras entre o público e privado. Belo Horizonte: Fórum, 2007.

PARANÁ. Constituição Estadual, de 5 de outubro de 1989. Diário Oficial [da] Estado do Paraná, Curitiba, PR, 5 out. 1989. Disponível em: $<$ https://www.legislacao.pr.gov.br/legislacao/exibirAto.do?action=iniciarProcesso\&codAto $=9779 \&$ codItemAto=97151 $>$. Acesso em: 15 fev. 2020 .

PEREIRA NETO, Caio Mario da Silva. Direito concorrencial. São Paulo: Saraiva, 2015.

SAITO, Carolina e DOUER, Zack. Grupos de compras: cooperação ou colusão?. Revista de Defesa da Concorrência, vol. 6, $\mathrm{n}^{\circ}$ 1, p. 120-155, maio 2018. ISSN 2318-2253. Disponível em: <http://revista.cade.gov.br/index.php/revistadedefesadaconcorrencia/issue/view/17> $\begin{array}{lllll}\text { Acesso } & \text { em } & 15 & \text { fev. } & 2020 .\end{array}$ http://revista.cade.gov.br/index.php/revistadedefesadaconcorrencia/article/view/370

TANAKA, Sônia Y. K. Sistema de credenciamento: hipótese de inexigibilidade de licitação: requisitos necessários: considerações. BLC - Boletim de Licitações e Contratos. São Paulo: Editora NDJ, maio 2003, p. 336. 